\title{
Early Continence and Extravasation After Open Retropubic Radical Prostatectomy - Interrupted vs Continuous Suturing for Vesicourethral Anastomosis
}

This article was published in the following Dove Press journal:

Therapeutics and Clinical Risk Management

\author{
Nora Köhler (D) \\ Nasrin El-Bandar \\ Andreas Maxeiner \\ Bernhard Ralla \\ Kurt Miller \\ Jonas Busch (1D* \\ Frank Friedersdorff* \\ Department of Urology, Charité- \\ Universitätsmedizin Berlin, Corporate \\ Member of Freie Universität Berlin, \\ Humbold-Universität Zu Berlin, and \\ Berlin Institute of Health, Berlin I0I I7, \\ Germany \\ *These authors contributed equally to \\ this work
}

Purpose: To compare running suture (RS) and interrupted suture (IS) of vesicourethral anastomosis (VUA) during open retropubic radical prostatectomy (RRP) on early urinary continence and extravasation.

Patients and Methods: Single center analysis of 211 patients who underwent RRP performed by a single surgeon during 2008 to 2017 was retrospectively analyzed. For VUA, we used the standard interrupted suture technique $(n=100)$ with a 3-0 PDS suture. The $R S(\mathrm{n}=111)$ was performed with 12-bite suture using 3-0 PDS. The primary endpoints were extravasation and early continence. Demographic and peri-operative data were collected and analyzed using Pearson's chi-square, $t$-Test and Mann-Whitney $U$-test. A binary logistic regression analysis was carried out to explore predictors that affected early continence after catheter removal.

Results: The rates of early urinary incontinence (UI) were $7.7 \%$ vs $42.2 \%(p<0.001)$. The duration of catheterization and hospitalization was significantly shorter in the interrupted group ( 4 days vs 5 days, $\mathrm{p}<0.001$ and 5 days vs 6 days, $\mathrm{p}<0.001$ ). The groups did not differ significantly in body mass index or prostate volume. There were older patients and higher PSA levels in the group with $R S$ technique. No significant difference was found in the postoperative extravasation rates between both groups $(13.5 \%$ vs $12 \%, \mathrm{p}=0.742)$.

Conclusion: Running vesicourethral anastomosis increased the rate of early urinary incontinence. Both anastomosis techniques provided a similar rate of postoperative urine extravasation. VUA should only be one of the many criteria that must be considered for the preservation of urinary continence of patients after RRP.

Keywords: retropubic prostatectomy, vesicourethral anastomosis, suturing technique, continence, tightness

\section{Introduction}

The aim of RRP in localized prostate cancer is to cure the patient, live long tumor freedom without biochemical recurrence, while maintaining urinary continence and erectile function. Postprostatectomy UI still remains one of the main side-effects with a negative impact on the patient's quality of life. ${ }^{1}$ The most technically challenging part of the procedure is the vesicourethral anastomosis (VUA). Anastomotic complications, such as insufficiency causing extravasation, are well known after RP. Urinary extravasation can cause a longer catheterization time,
Correspondence: Frank Friedersdorff Tel +4930450615219

Fax +4930450515910

Email frank.friedersdorff@charite.de
Therapeutics and Clinical Risk Management 2020:16 1289-1296

submit your manuscript DovePress if in $v$ http://doi.org/10.2147/TCRM.S278454 
which leads to patient discomfort and an increased risk of anastomotic strictures. ${ }^{2}$ Regaining urinary continence might also be delayed by a longer catheterization time. There are many reasons that can cause UI after RRP. In recent years the surgical techniques in RRP have improved by in the knowledge of the anatomy of the dorsal venous complex, the neurovascular bundles, prostate apex shape and urinary sphincter, the puboprostatic ligaments, length of the functional urethra and posterior rhabdosphincter as well as the description of the intrapelvic branch of the pudendal nerve. ${ }^{3-9}$

The vesicourethral anastomosis can be performed with either interrupted or running sutures. Jacobsen et al compared VUA in RRP and robot-assisted radical prostatectomy (RARP), with the idea that VUA in open RRP and RARP is performed with two different surgical techniques. Thus, there is a potential difference in the risk of anastomotic complications between the two types of procedures. ${ }^{10}$ Other studies compared IS and $R S$ for VUA in laparoscopic $\mathrm{RP}$, but there are only a few studies evaluating both suture techniques in open RRP. ${ }^{11-13}$ While data about mid- and long-term continence rates are available, studies about early continence rates after RP are rare. In consequence, the aim of the present study was to report data on early continence in patients undergoing open RRP and compare perioperative outcomes of the two anastomosis suture approaches.

\section{Patients and Methods}

\section{Study Population and Data Collection}

A retrospective review of 211 patients was carried out. Data were collected and approved according to the guidelines of the institutional review board "Ethikkomission Charité" (Berlin, Germany) which are based on the ICH Guideline for Good Clinical Practice and the declaration of the World Medical Association from 1964 (Helsinki) in their current version. Patient consent for review of medical records was not required because all data were deidentified. All patient data were treated anonymously.

All patients underwent open RRP due to histologically proven localized prostate cancer, performed by a single surgeon K.M. in a period from 2008 to 2017. Vesicourethral anastomosis was performed by running $(n=111)$ and interrupted suture $(n=100)$. There was no randomization. Since this is a retrospective work, all patients have already been operated on. Before 2010 the interrupted method was used, after that, we performed the continuous technique. Primary endpoints were early continence and VUA tightness. The tightness of the anastomosis was checked by postoperative cystography, escaping contrast medium was an indication of a leaking anastomosis. The endpoint of early urinary incontinence was assessed by anamnestic examination at the time of discharge (Ingelman-Sundberg classification). Residual urine quantities were determined by ultrasound.

Secondary endpoints were the period of hospitalization, frequency of postoperative complications (especially lymphoceles) and the time to catheter removal. Patients with pre-existing urinary incontinence were excluded.

\section{Surgical Techniques}

Open RRP was performed per Walsh's technique. ${ }^{14}$ Bladder neck preservation and nerve-sparing procedures were carried out when appropriate. For interrupted anastomosis suturing we used the technique described by Walsh with slight changes. ${ }^{14}$ Six stitches, using a 3-0 PDS suture, were made at 1, 3, 5, 7, 9 and 11 o'clock to implement the VUA (Figure 1).

Knotting the VUA with running suture was performed in imitation of Van Velthovens' technique - similar to running anastomotic suturing in laparoscopic radical prostatectomy (LRP) and RARP: We begin with a clockwise running suture starting at 3 o'clock, finishing at 9 o'clock. ${ }^{15}$ The needle is always driven in full-thickness from the outside into the bladder wall and from the inside out to the urethral stump. Care is taken to include mucosa with each pass without passing the everting sutures of the bladder neck. At this point a transurethral catheter is placed to facilitate placing the anterior anastomotic stitches. Subsequently, several passes are made through the anterior bladder neck and anterior urethra anticlockwise with a second 3-0 PDS suture, starting at 3 o'clock and finishing at 9 o'clock. In order to complete the anastomosis, the bladder neck and the urethra are merged together with gentle traction on the ends of the sutures and the anterior and posterior sutures are then tied to each other at 3 and 9 o'clock (Figures 2-4). After tying anastomosis, it is rinsed several times and checked for tightness during surgery.

\section{Statistical Analysis}

Demographic, clinical and pathological factors were compared between both groups. The individual parameters were examined by descriptive and inferential statistical calculations. Statistical analysis of the data was performed 


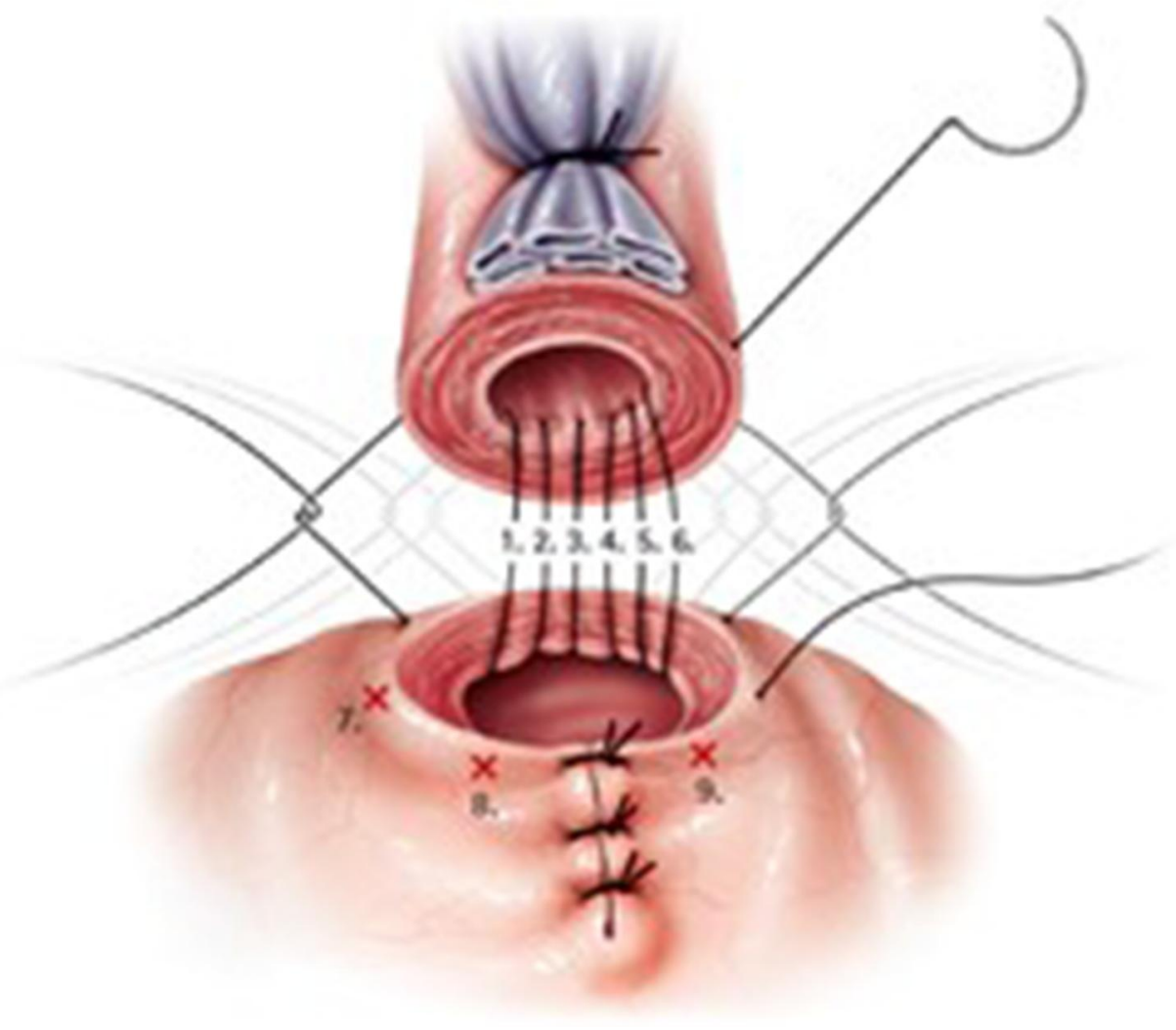

Figure I VUA technique with IR. (Image courtesy of @Stephan Spitzer, medizillu.de; https://www.spitzer-illustration.com/index.php).

using both Microsoft Office Excel 2007 and IBM SPSS Statistics 25 software.

The $t$-test for unrelated samples was used to test for significant differences in metric variables between two normally distributed groups, whereas the Mann-Whitney$U$ test was used to determine the significance of metric data in non-normally distributed samples. The Chi-square test was used for analyzing nominal parameters. For the binary logistic regression, the confidence level was set at $y=95 \%$. Results of all statistical tests with $p<0.05$ were considered significant.

\section{Results}

The demographic and baseline characteristics of the patients are summarized in Table 1. Median BMI was $25.7 \mathrm{~kg} / \mathrm{m} 2$ and the mean age was 65 years. There were higher PSA levels in the group with $R S$ technique, but similar prostate volumes for both groups.

Table 2 presents the perioperative data for both groups. The time of hospitalization and catheterization was significantly shorter in the interrupted group (five days vs six days and four days vs five days, $\mathrm{p}<0.001)$. Only two patients $(1.8 \%)$, both from the running group, showed intraoperative urinary extravasation. The rates of postoperative anastomotic extravasation were similar in both groups $(12 \%$ vs $13.5 \%, \mathrm{p}=0.742)$. Other postoperative complications occurred more often in the running group: there were significant differences regarding the appearance of lymphocele ( $3 \%$ vs $19.8 \%, \mathrm{p}<0.001)$ and residual urine ( $0 \%$ vs $8.1 \%, p=0.004)$. The early urinary incontinence rates were $7 \%$ (all grade $1 ;$ IR) and $42.2 \%$ (grade 1:24.5\%, grade 2: $13.7 \%$, grade 3: $3.9 \%$; RS). The chance of patients suffering from early incontinence in the running group was eleven times higher than for patients in the interrupted group (OR 11.008; 95\% CI 3.388-35.760; $\mathrm{p}<0.001)$. The neuro safe technique correlates significantly $(\mathrm{p}=0.03$ ) with early continence (OR 0.209 ; CI 95\% 0.051-0.862). Age (OR 1.009, 95\% CI 0.958-1.061, $\mathrm{p}=0.74$ ), BMI (OR 1.105, 95\% CI 0.994-1.228, $\mathrm{p}=0.065$ ) and the reconstruction of the bladder neck (OR 1.044, 95\% CI $0.372-2.931, \mathrm{p}=0.935$ ) had no impact on early continence. The distribution of the nerve-sparing technique was $74.5 \%$ (RS) vs $98 \%$ (IS).

Nerve preservation, compared to non-nerve-sparing, has positive influence on continence with statistical significance (OR $0.209 ; 95 \%$ CI $0.051-0.862 ; \mathrm{p}=0.03$ ). The 


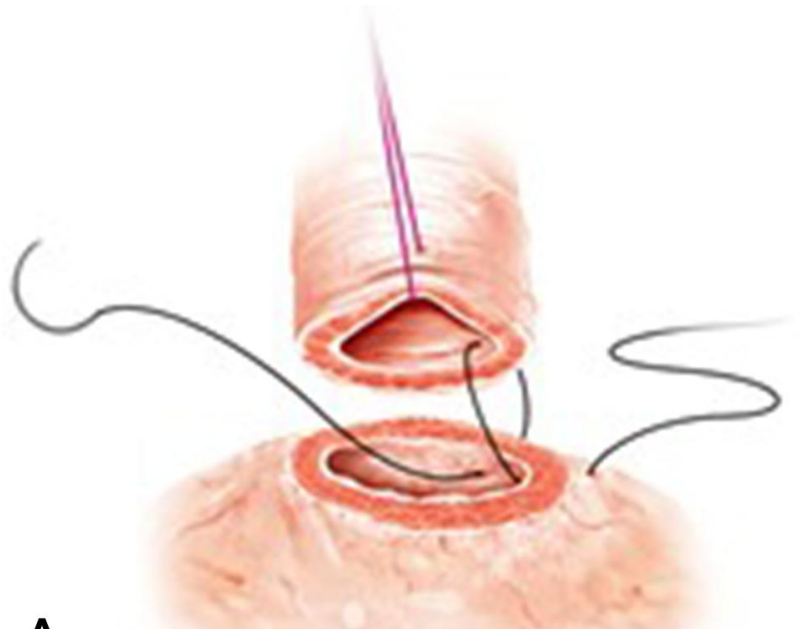

A

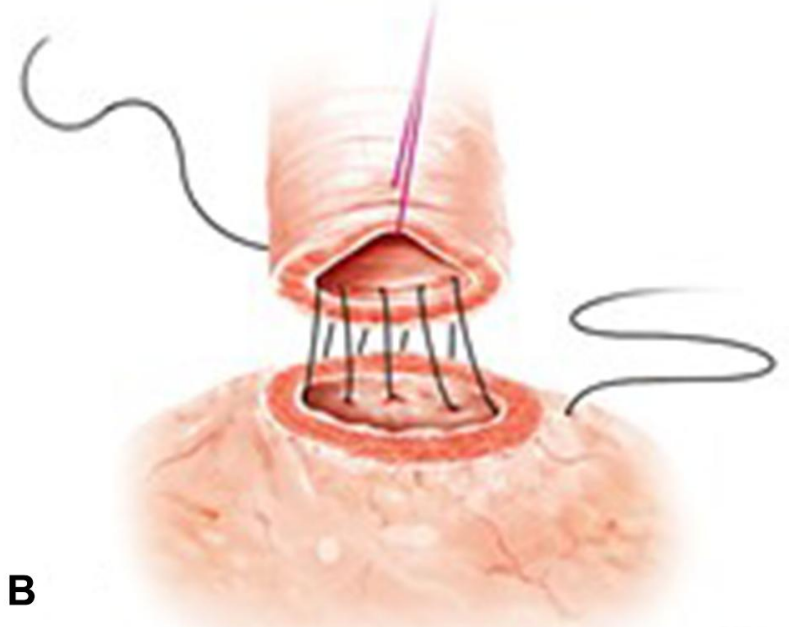

Figure 2 VUA technique with RS. (A) First stitch at 3 o'clock. (B) Posterior anastomotic suture (Image courtesy of CStephan Spitzer, medizillu.de; https:// www.spitzer-illustration.com/index.php).

chance of incontinence in patients with partial nervesparing is 0.26 times higher compared to patients without nerve-sparing. However, this effect is not significant $(\mathrm{p}=0.14)$.

The operating time was $2: 54$ vs $2: 35(\mathrm{p}=0.091)$ but we could not determine the suturing time for VUA.

\section{Discussion}

The aim of RRP is to achieve adequate oncological outcomes while keeping postoperative complications to a minimum and ensuring the quality of life of patients by maintaining urinary continence and potency. VUA is one of the decisive steps in preserving urinary continence after RRP. Various anastomosis techniques have been described
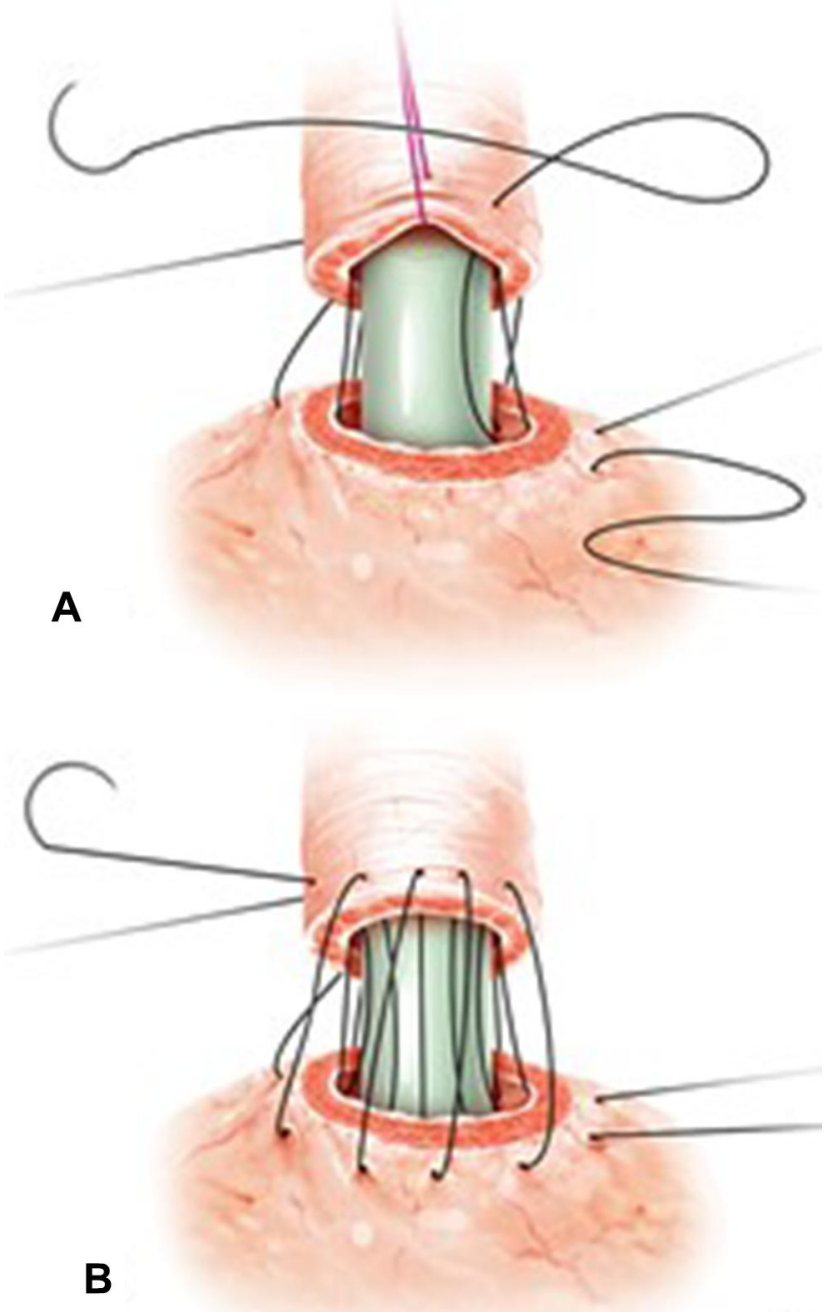

Figure 3 VUA technique with RS. (A) Continuing the suture after placing a transurethral catheter. (B) Anterior anastomotic suture (Image courtesy of (CStephan Spitzer, medizillu.de; https://www.spitzer-illustration.com/index.php).

in the literature. The vest technique was used to remove tension from the anastomosis. ${ }^{16}$ Studies also assessed the variation in the number of stitches for VUA. ${ }^{17,18}$ It was shown that using a low number of stitches results in a reduced operating time without influencing perioperative parameters. Simforoosh et al even presented a sutureless anastomosis technique with good outcomes. ${ }^{19}$ Various considerations, technical features and improvements for vesicourethral anastomosis were explained by Gillizter and Thüroff. ${ }^{20}$

The two most commonly used techniques are $R S$ and IS. $^{21}$ Both running and interrupted sutures have specific advantages and disadvantages. Continuous suturing is considered the faster method with a possible reduction of anastomotic leakage, as has been shown in other medical 

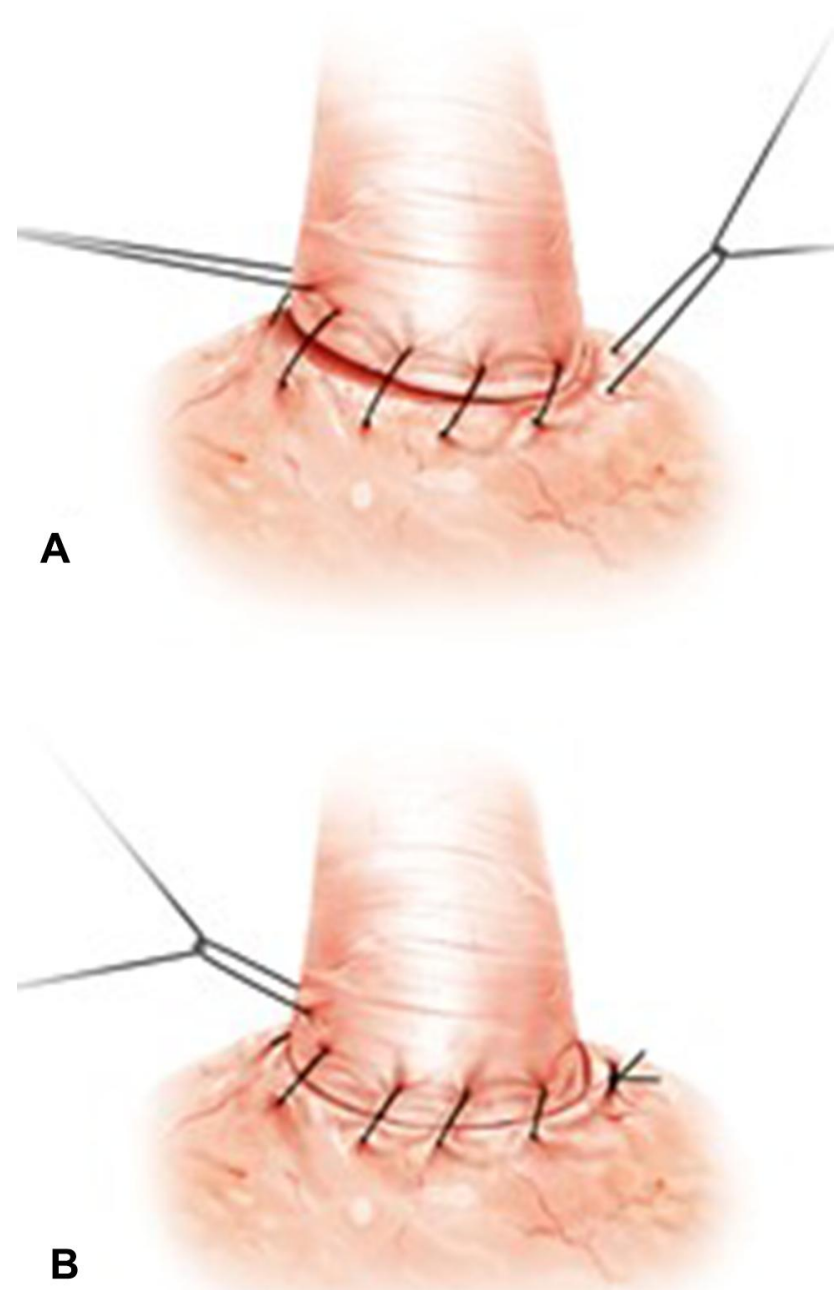

Figure 4 VUA technique with RS. (A) Approximation of urethra and bladder neck. (B) Knotting (Image courtesy of OStephan Spitzer, medizillu.de; https://www.spit zer-illustration.com/index.php).

fields. ${ }^{22}$ Some of these advantages - especially regarding the suturing time - were also seen in prostatectomy. Comparison between $R S$ and IS for vesicourethral anastomosis in RARP and LRP showed a shorter anastomotic suturing time when using the running technique. ${ }^{23-25}$ Unfortunately, the time needed to conduct the anastomotic suture could not be determined in the present study. Only the operating time was documented. Surgery time was higher in the $R S$ group which may be related to the higher number of pT3 (57 versus 38 ). That could also be responsible for the higher number of lymphoceles in the $R S$ group (19.8 vs 3\%). This is also confirmed in higher Gleason scores and pT stadium.

Studies show a significant superiority of the $R S$ in laparoscopic RP in terms of catheterization time. ${ }^{26-28}$ In
Table I Comparison of Patient Characteristics and Pathologic Data

\begin{tabular}{|l|l|l|l|}
\hline Parameters & RS (n=I I I) & IS (n= 100) & p-value \\
\hline Age (y) M(SD) & $67(8)$ & $63(7)$ & $<0.00 I^{+}$ \\
BMI (kg/m2) MED(IQA) & $26(24-28)$ & $26(25-28)$ & $0.316^{\#}$ \\
Hypertension n (\%) & $57(51.4)$ & $37(37)$ & $0.036^{*}$ \\
Coronary heart disease n (\%) & $9(8.1)$ & $8(8)$ & $0.977^{*}$ \\
Diabetes mellitus II n (\%) & $7(6.3)$ & $10(10)$ & $0.325^{*}$ \\
Prostate volume (mL) & $42(35-52.75)$ & $40(30-50)$ & $0.185^{\#}$ \\
MED(IQA) & & & \\
PSA (ng/mL) MED(IQA) & $9(6-16)$ & $6.7(5.19-11.66)$ & $0.004^{\#}$ \\
\hline Gleason Score & & & $0.008^{+}$ \\
Gleason 6 n (\%) & $6(5.5)$ & $21(21)$ & \\
Gleason 7 n (\%) & $75(68.2)$ & $60(60)$ & \\
Gleason 8-10 (n\%) & $29(26.4)$ & $19(19)$ & \\
\hline PT & & & $0.007^{*}$ \\
PT2a n (\%) & $4(3.6)$ & $18(18)$ & \\
PT2b n (\%) & $2(1.8)$ & $0(0)$ & \\
PT2c n (\%) & $47(42.7)$ & $43(43)$ & \\
PT3a n (\%) & $31(28.2)$ & $18(18)$ & \\
PT3b n (\%) & $26(23.6)$ & $20(20)$ & \\
PT4 n (\%) & $0(0)$ & $1(1)$ & \\
\hline
\end{tabular}

Notes: ${ }^{+}$t-test, ${ }^{\#}$ Mann-Whitney- $U$ test, ${ }^{*}$ Chi Square test.

contrast, the duration of postoperative catheterization in our study differed significantly by one day in favour of the interrupted group (median 4 days vs 5 days).

Similarly, to our approach, Lim et al investigated the suturing technique (RS vs IS) of VUA in open RRP in a single surgeon study. In addition to catheterization time and the occurrence of extravasation, urinary continence was examined after three, six, nine and 12 months after RRP. The groups did not differ regarding extravasation and continence. ${ }^{11}$ These results are partly consistent with the observations presented in our study: the rates of postoperative extravasation were similar for both groups. $86.5 \%$ (RS) and $88.0 \%$ (IS) showed no leakage in the cystography. Only two patients receiving a continuous suture $(1.8 \%)$ showed intraoperative urinary extravasation. However, the rate of intraoperative extravasation is small, and the occurrence of postoperative anastomotic extravasation was similar in both groups.

In general, controversial results were found for the rate of extravasation. In a study conducted by Matsuyama et al $43 \%$ of the patients in the IS group showed extravasation in the cystography. This contrasts with only $10 \%$ in the $R S$ group. ${ }^{12}$ In contrast, Poulakis et al presented a lower rate of extravasation for IS, while Cohen et al presented advantages of the $R S$ for both extra- and transperitoneal 
Table 2 Postoperative Parameters

\begin{tabular}{|c|c|c|c|}
\hline Parameters & $\begin{array}{l}\text { RS } \\
(n=|I|)\end{array}$ & $\begin{array}{l}\text { IS } \\
(n=100)\end{array}$ & p-value \\
\hline $\begin{array}{l}\text { Tightness of VUA n (\%) } \\
\text { Hospitalization time (d) } \\
\text { MED(IQA) }\end{array}$ & $\begin{array}{l}96(86,5) \\
6(5-7)\end{array}$ & $\begin{array}{l}88(88) \\
5(4-6)\end{array}$ & $\begin{array}{l}0.742^{*} \\
<0.00 I^{\#}\end{array}$ \\
\hline $\begin{array}{l}\text { Early incontinence n (\%) } \\
\qquad \text { I n (\%) } \\
\text { II n (\%) } \\
\text { III n (\%) }\end{array}$ & $\begin{array}{l}43(42.2) \\
25(24.5) \\
14(13.7) \\
4(3.9)\end{array}$ & $\begin{array}{l}7(7.7) \\
7(7.7) \\
0(0) \\
0(0)\end{array}$ & $<0.001 *$ \\
\hline $\begin{array}{l}\text { Urinary retention } \mathrm{n}(\%) \\
\text { Urinary tract infection } \mathrm{n}(\%) \\
\text { Residual urine } \mathrm{n}(\%) \\
\text { Lymphocele } \mathrm{n}(\%)\end{array}$ & $\begin{array}{l}12(10.8) \\
5(4.5) \\
9(8.1) \\
22(19.8)\end{array}$ & $\begin{array}{l}6(6) \\
2(2) \\
0(0) \\
3(3)\end{array}$ & $\begin{array}{l}0.212^{*} \\
0.310^{*} \\
0.004^{*} \\
<0.001 *\end{array}$ \\
\hline $\begin{array}{l}\text { Clavien Dindo } \\
\text { Clavien Dindo I n (\%) } \\
\text { Clavien Dindo II n (\%) } \\
\text { Clavien Dindo IIla n (\%) } \\
\text { Clavien Dindo IIlb n (\%) }\end{array}$ & $\begin{array}{l}34(30.6) \\
8(7.2) \\
7(6.3) \\
11(9.9)\end{array}$ & $\begin{array}{l}19(19) \\
4(4) \\
1(1) \\
2(2)\end{array}$ & $<0.001 *$ \\
\hline $\begin{array}{l}\text { Catheterization time (d) } \\
\text { MED(IQA) }\end{array}$ & $5(4-7)$ & $4(4-4)$ & $<0.001^{\#}$ \\
\hline $\begin{array}{l}\text { R } \\
\text { R0 } \\
\text { RI } \\
\text { R2 }\end{array}$ & $\begin{array}{l}78(70.1) \\
31(28.2) \\
I(0.9)\end{array}$ & $\begin{array}{l}68(69.4) \\
29(29.6) \\
I(1)\end{array}$ & $0.97 I *$ \\
\hline
\end{tabular}

Notes: "Mann-Whitney-U test, ${ }^{*}$ Chi Square test.

procedures. ${ }^{23,24}$ The continence status presented by Matsuyama et al is also contrary to the present observations: $21.8 \%$ in the running group suffered from urinary incontinence at the time of discharge. A significantly higher incontinence rate of $36.5 \% \quad(p=0.0384)$ was observed in patients of the interrupted group. One month postoperatively the difference was still significant in favour of the $R S$ technique ( $\mathrm{p}=0.0463$ ). After three, six and 12 months, no significant differences could be detected. ${ }^{12}$

In the present study, the rate of urinary incontinence of all severity levels was between $7.7 \%$ (IS) and $42.2 \%$ (RS). However, these figures only refer to early incontinence. Due to missing data, the survey of urinary continence after three, six, nine and 12 months was not performed for our patient collective. We assume that the suture technique has no influence on the late continence rate as previously investigated and shown by other authors. ${ }^{21}$ There are several aspects that may have contributed to the higher early incontinence rate in the $R S$ group. Higher PSA levels, a higher age and a longer hospitalization period were seen in the $R S$ group and may be related to the unfavourable outcome regarding early continence. This is confirmed in the publication of Campodonico et al. ${ }^{29}$

Recovery of urinary incontinence should be considered as a process that extends well beyond the hospital stay. While there is little data on early incontinence, the literature allows a clearer assessment of the urinary continence situation of patients in the course of time after RP: the majority of patients are continent three months after surgery. The continence rates one year after surgery is up to $90 \%{ }^{30-32}$ It can therefore be assumed that the incontinence rate of the running group improved in due course.

The present study had some limitations as the findings represent the clinical experience of a single center and a single surgeon. On the other hand, a very experienced urologist was selected to avoid distortion by multiple surgeons. In addition, the small number of patients limited the value of the statistical calculations. Furthermore, the study design was retrospective and non-randomized. Some baseline clinical characteristics of the patients were different between the two groups which led to limited comparability. Furthermore, our study lacks long-term follow-up to compare very early and long-term continence rates. We suggest that prospective randomized trials that include a larger patient population are necessary.

\section{Conclusions}

Interrupted and continuous suturing are safe techniques for tying the vesicourethral anastomosis during open RRP. Both anastomosis techniques provided a similar rate of postoperative urine extravasation. However, running vesicourethral anastomosis increased the rate of early urinary incontinence. Therefore, VUA should only be one of the many criteria that must be taken into account for the preservation of urinary continence of patients after RRP. Choosing the suture technique should be based on surgeon's technical approach and experience.

\section{Acknowledgments}

We thank H. Cash for his input as native speaker. We acknowledge support from the German Research Foundation (DFG) and the Open Access Publication Fund of Charité - Universitätsmedizin Berlin.

\section{Disclosure}

The authors report no conflicts of interest in this work. 


\section{References}

1. Litwin MS, Pasta DJ, Yu J, Stoddard ML, Flanders SC. Urinary function and bother after radical prostatectomy or radiation for prostate cancer: a longitudinal, multivariate quality of life analysis from the cancer of the prostate strategic urologic research endeavor. $J$ Urol. 2000;164(6):1973-1977. doi:10.1016/S0022-5347(05)66931-5

2. Beck V, Apfelbeck M, Chaloupka M, Kretschmer A, Strittmatter F, Tritschler S. Stricture of the vesicourethral anastomosis after radical prostatectomy. Urologe A. 2018;57(1):29-33. doi:10.1007/s00120017-0550-x

3. Reiner WG, Walsh PC. An anatomical approach to the surgical management of the dorsal vein and santorini's plexus during radical retropubic surgery. $J$ Urol. 1979;121(2):198-200. doi:10.1016/ S0022-5347(17)56718-X

4. Myers RP, Goellner JR, Cahill DR. Prostate shape, external striated urethral sphincter and radical prostatectomy: the apical dissection. $J$ Urol. 1987;138(3):543-550. doi:10.1016/S00225347(17)43253-8

5. Steiner MS. The puboprostatic ligament and the male urethral suspensory mechanism: an anatomic study. Urology. 1994;44 (4):530-534. doi:10.1016/S0090-4295(94)80052-9

6. Rocco F, Carmignani L, Acquati P, et al. Restoration of posterior aspect of rhabdosphincter shortens continence time after radical retropubic prostatectomy. J Urol. 2006;175(6):2201-2206. doi:10.1016/ S0022-5347(06)00262-X

7. Hollabaugh RS, Dmochowski RR, Kneib TG, Steiner MS. Preservation of putative continence nerves during radical retropubic prostatectomy leads to more rapid return of urinary continence. Urology. 1998;51(6):960-967. doi:10.1016/S00904295(98)00128-9

8. Ficarra V, Novara G, Rosen RC, et al. Systematic review and meta-analysis of studies reporting urinary continence recovery after robot-assisted radical prostatectomy. Eur Urol. 2012;62(3):405-417. doi:10.1016/j.eururo.2012.05.045

9. Schlomm T, Heinzer H, Steuber T, et al. Full functional-length urethral sphincter preservation during radical prostatectomy. Eur Urol. 2011;60(2):320-329. doi:10.1016/j.eururo.2011.02.040

10. Jacobsen A, Berg KD, Iversen P, Brasso K, Røder MA. Anastomotic complications after robot-assisted laparoscopic and open radical prostatectomy. Scand J Urol. 2016;50(4):274-279.

11. Lim JH, Park CM, Kim HK, Park JY. Comparison of perioperative outcomes between running versus interrupted vesicourethral anastomosis in open radical prostatectomy: a single-surgeon experience. Korean J Urol. 2015;56(6):443-448. doi:10.4111/ kju.2015.56.6.443

12. Matsuyama H, Matsumoto H, Nagao K, Harada N, Hara T, Sakano S. Running suture versus interrupted suture for vesicourethral anastomosis in retropubic radical prostatectomy: a randomized study. Int J Urol. 2015;22(3):271-277. doi:10.1111/iju.12667

13. Lee SW, Han DH, Lee KS, Jeon SS. Effect of continuous urethro-vesical anastomosis technique in incontinence after radical retropubic prostatectomy, 1:1 matching study. Int Neurourol J. 2015;19(2):113-119. doi:10.5213/inj.2015.19.2.113

14. Walsh PC. Anatomic radical prostatectomy: evolution of the surgical technique. J Urol. 1998;160(6 Pt 2):2418-2424. doi:10.1016/S0022$5347(01) 62202-X$

15. Van Velthoven RF, Ahlering TE, Peltier A, Skarecky DW, Clayman RV. Technique for laparoscopic running urethrovesical anastomosis: the single knot method. Urology. 2003;61(4):699-702. doi:10.1016/S0090-4295(02)02543-8

16. Novicki DE, Larson TR, Andrews PE, Swanson SK, Ferrigni RG. Comparison of the modified vest and the direct anastomosis for radical retropubic prostatectomy. Urology. 1997;49(5):732-736. doi:10.1016/S0090-4295(97)00066-6
17. Gallo L, Perdonà S, Autorino R, et al. Vesicourethral anastomosis during radical retropubic prostatectomy: does the number of sutures matter? Urology. 2007;69(3):547-551. doi:10.1016/j. urology.2006.12.016

18. Mazaris EM, Chatzidarellis E, Varkarakis IM, Dellis A, Deliveliotis C. Reducing the number of sutures for vesicourethral anastomosis in radical retropubic prostatectomy. Int Braz J Urol. 2009;35(2):158-163. doi:10.1590/S1677-55382009000200005

19. Simforoosh N, Javaherforooshzadeh A, Aminsharifi A, Tabibi A. Early continence after open and laparoscopic radical prostatectomy with sutureless vesicourethral alignment: an alternative technique, 8 years' experience. Urol J. 2009;6(3):163-169.

20. Gillitzer R, Thüroff JW. Technical advances in radical retropubic prostatectomy techniques for avoiding complications. Part II: vesico-urethral anastomosis and nerve-sparing prostatectomy. BJU Int. 2003;92(2):178-184. doi:10.1046/j.1464-410X.2003.04283.x

21. Kowalewski KF, Tapking C, Hetjens S, et al. Interrupted versus continuous suturing for vesicourethral anastomosis during radical prostatectomy: a systematic review and meta-analysis. Eur Urol Focus. 2019;5(6):980-991. doi:10.1016/j.euf.2018.05.009

22. Lee S-E, Yang S-H, Jang J-Y, Kim S-W. Pancreatic fistula after pancreaticoduodenectomy: a comparison between the two pancreaticojejunostomy methods for approximating the pancreatic parenchyma to the jejunal seromuscular layer: interrupted vs continuous stitches. World J Gastroenterol. 2007;13(40):5351-5356. doi:10.3748/wjg.v13.i40.5351

23. Poulakis V, Skriapas K, de Vries R, Dillenburg W, Witzsch U, Becht E. Vesicourethral anastomosis during endoscopic extraperitoneal radical prostatectomy: a prospective comparison between the single-knot running and interrupted technique. Urology. 2006;68 (6):1284-1289. doi:10.1016/j.urology.2006.08.1063

24. Cohen MS, Triaca V, Silverman ML, Tuerk IA. Progression of laparoscopic radical prostatectomy: improved outcomes with the extraperitoneal approach and a running anastomosis. $J$ Endourol. 2006;20(8):574-579. doi:10.1089/end.2006.20.574

25. Massoud W, Thanigasalam R, El Hajj A, et al. Does the use of a barbed polyglyconate absorbable suture have an impact on urethral anastomosis time, urethral stenosis rates, and cost effectiveness during robot-assisted radical prostatectomy? Urology. 2013;82(1):90-94. doi:10.1016/j.urology.2013.02.002

26. Teber D, Erdogru T, Cresswell J, Gözen AS, Frede T, Rassweiler JJ. Analysis of three different vesicourethral anastomotic techniques in laparoscopic radical prostatectomy. World J Urol. 2008;26(6):617. doi:10.1007/s00345-008-0281-0

27. Erdoğru T, Teber D, Rassweiler J. Different two vesicourethral anastomosis techniques in laparoscopic radical prostatectomy: match-pair analysis. Turk J Urol. 2004;30:426-431.

28. Juan Escudero JU, Ramírez Backhaus M, Benedicto Redón A. Use of a barbed suture for the urethro-vesical anastomosis during the learning curve of the endoscopic extraperitoneal radical prostatectomy. Arch Esp Urol. 2012;65(8):752-758.

29. Campodonico F, Manuputty EE, Campora S, Puntoni M, Maffezzini M. Age is predictive of immediate postoperative urinary continence after radical retropubic prostatectomy. Urol Int. 2014;92 (3):276-281. doi:10.1159/000353414

30. Kowalewski KF, Tapking $\mathrm{C}$, Hetjens $\mathrm{S}$, et al. Interrupted versus continuous suturing for vesicourethral anastomosis during radical prostatectomy: protocol for a systematic review and meta-analysis. BMJ Open. 2017;7(11):e019823.

31. Kuehhas FE, Naegele R, Eckersberger E, et al. Urinary continence after radical prostatectomy: the patient perspective. Can J Urol. 2011;18(4):5811-5818.

32. Zorn KC, Wille MA, Thong AE, et al. Continued improvement of perioperative, pathological and continence outcomes during 700 robot-assisted radical prostatectomies. Can J Urol. 2009;16 (4):4742-4749. 


\section{Publish your work in this journal}

Therapeutics and Clinical Risk Management is an international, peerreviewed journal of clinical therapeutics and risk management, focusing on concise rapid reporting of clinical studies in all therapeutic areas, outcomes, safety, and programs for the effective, safe, and sustained use of medicines. This journal is indexed on PubMed Central, CAS,
EMBase, Scopus and the Elsevier Bibliographic databases. The manuscript management system is completely online and includes a very quick and fair peer-review system, which is all easy to use. Visit http://www.dovepress.com/testimonials.php to read real quotes from published authors. 